Article

\title{
Exploring Needle-Like Zinc Oxide Nanostructures for Improving Dental Resin Sealers: Design and Evaluation of Antibacterial, Physical and Chemical Properties
}

\author{
Fabrício M Collares ${ }^{1, *(\mathbb{D})}$, Isadora M Garcia ${ }^{1} \mathbb{D}$, Mariana Klein ${ }^{1}$, Clarissa F Parolo ${ }^{2}$, \\ Felipe Antonio L Sánchez ${ }^{3}$, Antônio Takimi ${ }^{4}$, Carlos P Bergmann ${ }^{3}$, Susana Maria W Samuel ${ }^{1}$, \\ Mary Anne Melo ${ }^{5,6, *(D)}$ and Vicente CB Leitune ${ }^{1}$ (D) \\ 1 Dental Materials Laboratory, School of Dentistry, Federal University of Rio Grande do Sul, Rua Ramiro \\ Barcelos, 2492, Rio Branco, Porto Alegre 90035-003, RS, Brazil; isadora.garcia@ufrgs.br (I.M.G.); \\ mariana.klein@ufrgs.br (M.K.); susana.samuel@ufrgs.br (S.M.W.S.); vicente.leitune@ufrgs.br (V.C.B.L.) \\ 2 Biochemistry and Microbiology Laboratory, School of Dentistry, Federal University of Rio Grande do Sul, \\ Rua Ramiro Barcelos, 2492, Rio Branco, Porto Alegre 90035-003, RS, Brazil; clarissa.parolo@ufrgs.br \\ 3 Laboratory of Ceramic Materials, Federal University of Rio Grande do Sul, Av. Osvaldo Aranha, 99, \\ Porto Alegre 90035-190, RS, Brazil; felipe.sanchez@ufrgs.br (F.A.L.S.); carlos.bergmann@ufrgs.br (C.P.B.) \\ 4 Laboratory for Electrochemical Processes and Corrosion, Engineering School, Federal University of Rio \\ Grande do Sul, Bento Gonçalves, 9500, Prédio 43427, Sala 216, Porto Alegre 91501-970, RS, Brazil; \\ antonio.takimi@gmail.com \\ 5 Ph.D. Program in Biomedical Sciences, University of Maryland School of Dentistry, \\ Baltimore, MD 21201, USA \\ 6 Operative Dentistry Division, General Dentistry Department University of Maryland School of Dentistry, \\ Baltimore, MD 21201, USA \\ * Correspondence: fabricio.collares@ufrgs.br (F.M.C.); mmelo@umaryland.edu (M.A.M.)
}

Received: 9 March 2020; Accepted: 25 March 2020; Published: 2 April 2020

check for updates

\begin{abstract}
This study aimed to evaluate the effect of needle-like zinc oxide nanostructures ( $\mathrm{ZnO}-\mathrm{NN}$ ) on the physical, chemical, and antibacterial properties of experimental methacrylate-based dental sealers. ZnO-NN was synthesized and characterized. ZnO-NN was added to a co-monomer blend at 20, 30, and $40 \mathrm{wt} . \%$. One group without $\mathrm{ZnO}-\mathrm{NN}$ was used as a control. The dental resin sealers were evaluated for their flow, film thickness, water sorption, solubility, radiopacity, degree of conversion (DC), dental-sealer interface characterization via micro-Raman, and antibacterial activity. $\mathrm{ZnO}-\mathrm{NN}$ presented a mean needle diameter of $40 \mathrm{~nm}$ and $16 \mathrm{~m}^{2} / \mathrm{g}$ of surface area. There was no difference among groups containing $\mathrm{ZnO}-\mathrm{NN}$ regarding their flow. The $\mathrm{ZnO}-\mathrm{NN}$ addition significantly increased the film thickness. Water sorption and solubility tests showed no difference among groups. The radiopacity increased, and DC decreased with higher concentrations of ZnO-NN. Micro-Raman suggested that ZnO-NN was in close contact with root canal dentin. Overall, the incorporation of $\mathrm{ZnO}-\mathrm{NN}$ provided an antibacterial effect against Enterococcus faecalis without a significant detrimental impact on the physical and chemical functionality of the material. The use of ZnO-NN as an inorganic filler is a potential application within dental materials intended for root canal treatment.
\end{abstract}

Keywords: methacrylate-based materials; zinc oxide; Biopolymers; root canal filling materials; Antimicrobial agents; dental materials 


\section{Introduction}

Nanomaterials have received widespread attention for dental applications partly because they exhibit improved or new functionality in comparison to their microsized counterparts [1-3]. In dentistry, macro and micro-sized zinc oxide $(\mathrm{ZnO})$ are well-stabilized inorganic fillers and have been tested in dental materials. Sealers and cement (zinc oxide-eugenol and zinc phosphate cement) $[4,5]$, composites [6], and adhesive resins [7] are among the materials in which $\mathrm{ZnO}$ has been explored.

As biointeractive fillers, nanosized $\mathrm{ZnO}$ particles can enable mineral growth via bioactivity and negatively affect metalloproteinases and bacteria growth [8-10]. Particles with nanometer-sizes present a high surface area and increased surface reactivity due to a higher percentage of atoms on the material's surface [11]. Therefore, their biological properties may be intrinsically associated with their low dimensionality and higher reactivity $[1,12]$. Moreover, the decreased size of fillers can lead to different physical and chemical properties of materials [7].

Over the past decade, the synthesis, characterization, and potential biomedical applications of one-dimensional nanostructure $\mathrm{ZnO}$ have been studied [13,14]. A large variety of $\mathrm{ZnO}$ nanostructures, such as nanoamorphous particles, nanowires, nanotubes, and nanofibers, has been prepared [15]. Also, some novel $\mathrm{ZnO}$ with complex architectures, such as nanocombs, nanosprings, nanoneedles, nanopropellers, tetrapods- and flower/urchin-like nanostructures have been reported in the literature up to date [16]. The variability on the morphology of $\mathrm{ZnO}$ has been explored as a pathway for the development of new properties, investigations of cell adhesion, and promising improved antibacterial effect $[17,18]$.

The antibacterial performance of $\mathrm{ZnO}$ nanostructures depends on their size and shape, surface-to-volume ratio, and the number of oxygen vacancy sites [1,19]. ZnO nanostructures hamper the growth of Enterococcus faecalis, an essential bacterium in the post-infection of root canal treated teeth, and failure of treatment [20]. This antibacterial activity occurs via membrane disorganization and gene downregulation promoted by $\mathrm{ZnO}[18,21]$. These outcomes are exciting and lead to the questioning of whether $\mathrm{ZnO}$ nanostructures could be used as bioactive inorganic fillers in dental sealers for root canal treatment. However, the maintenance of a range of functionalities of dental sealers during the root canal obturation is essential to attain the desired treatment outcome. Ideally, dental sealers should be capable of (1) penetrating and sealing the dentinal tubules; (2) binding intimately to both the organic and inorganic phases of dentin; (3) decreasing microorganisms viability and neutralizing their products; (4) predictably inducing a regenerative response, and (5) strengthening the root complex system [22,23].

Nanostructured needle-like zinc oxide ( $\mathrm{ZnO}-\mathrm{NN})$ presents extensions originating from one nucleation core with distinct directions within a three-dimensional space [24]. This structure results in a uniform dispersion and homogeneous stress distribution into the materials, which may reflect in their reinforcement [25]. Subsequently, the prospects of using nanostructures of $\mathrm{ZnO}$ with needle-like shapes may be an exciting step to achieve better dental sealers for endodontics (Figure 1).

Based on the above consideration, this study reports the synthesis of needle-like zinc oxide nanostructures $(\mathrm{ZnO}-\mathrm{NN})$ particles and their incorporation into an experimental methacrylate-based dental sealer for root canal treatment for the first time. This study aimed to assist the investigators in determining whether a candidate $\mathrm{ZnO}$ nanostructure has scientific merit to justify further investigations and applicability. For this purpose, we evaluated the dental sealers for the following physical, chemical, or biological properties: flow, film thickness, water sorption, and solubility, radiopacity, degree of conversion, root-sealer interface, and antibacterial effects against E. faecalis. 


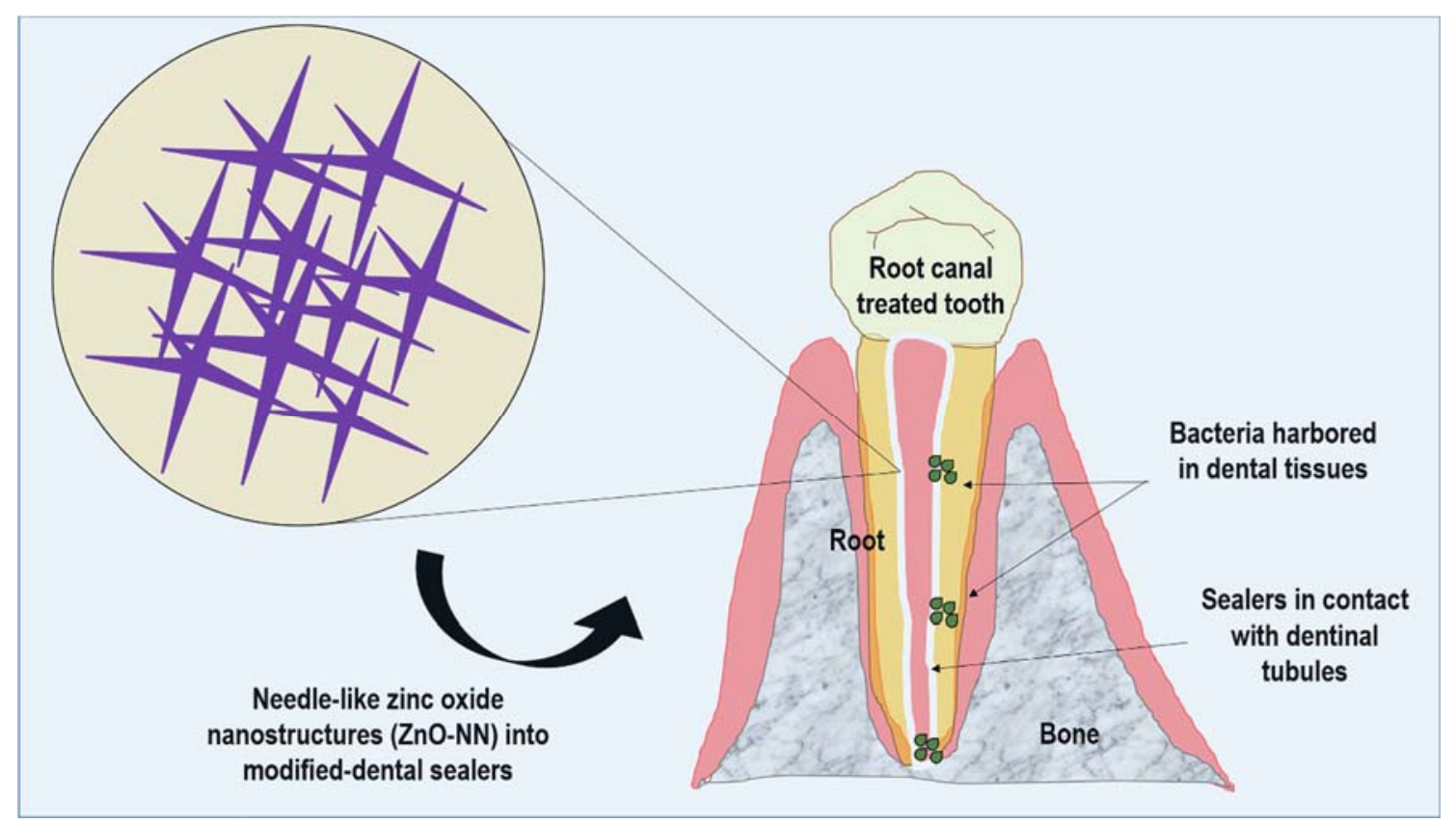

Figure 1. Schematic representation of the proposed approach of needle-like zinc oxide nanostructures (ZnO-NN) for improving dental resin sealers.

\section{Materials and Methods}

\subsection{Synthesis of Needle-Like Zinc Oxide Nanostructures ( $\mathrm{ZnO}-\mathrm{NN}$ )}

Needle-like zinc oxide nanostructures were prepared by a simple thermal evaporation method, according to a previous study [26]. Briefly, $\mathrm{ZnO}$ powder mixed with graphite (molar ratio 1:1) was placed at the closed end of the quartz tube and then inserted into a horizontal tube furnace heated to $1100{ }^{\circ} \mathrm{C}$. The temperature gradient at the location between the source material and the open end of the quartz tube was approximately $600^{\circ} \mathrm{C}$. After $30 \mathrm{~min}$ of evaporation, the quartz tube was removed from the furnace and left to cool down at room temperature. White color power was observed in the inner walls of the quartz tube. Particle size and particle shape were analyzed by scanning electron microscopy (TM3000 model, Hitachi High-Technologies, Naha-shi, Okinawa, Japan). The Brunauer-Emmett-Teller (BET) method was used to analyze the specific surface area via an automated gas sorption system (Quantachrome NOVA1000 Autosorb, Boynton Beach, FL, USA).

\subsection{Resin Sealers Formulation}

The experimental dental sealers were formulated using urethane dimethacrylate (UDMA), glycerol-1,3-dimethacrylate (GDMA), ethoxylated bisphenol A glycol dimethacrylate (BISEMA), camphorquinone (CQ), N, N-dihydroxy ethyl-para-toluidine (DHEPT) and benzoyl peroxide (BP). These materials were used without further processing. Table 1 describes the chemical composition of the formulations assessed in this study. ZnO-NN was added at three different weight ratios $(20,30$, or $40 \mathrm{wt} . \%$ ) over the total quantity of base resin (monomers and photoinitiator system). One group without the addition of $\mathrm{ZnO}-\mathrm{NN}$ was used as a control. The mixture (base resin/ZnO-NN) was hand-mixed for $60 \mathrm{~s}$, sonicated for $90 \mathrm{~s}$, and hand-mixed again for $60 \mathrm{~s}$. A light-emitting diode activation unit (1200 $\mathrm{mW} \mathrm{cm}^{-2}$, Radii; SDI, Bayswater, Australia) was used to photoactivate the sealers along with all study. 
Table 1. Description of the components and primary role of each substance used to formulate the base resin of dental sealer formulations.

\begin{tabular}{|c|c|c|c|c|}
\hline Chemical Component Description & Abbreviation & Manufacturer & Role of each Substance & Content \\
\hline Urethane dimethacrylate & UDMA & Sigma-Aldrich, St Louis, MO, USA & Co-monomeric blend composition & 70.00 wt. $\%$ \\
\hline Glycerol-1,3-dimethacrylate & GDMA & Sigma-Aldrich, St Louis, MO, USA & Co-monomeric blend composition & 15.00 wt. $\%$ \\
\hline $\begin{array}{l}\text { Ethoxylated bisphenol A glycol } \\
\text { dimethacrylate }\end{array}$ & BISEMA & Sigma-Aldrich, St Louis, MO, USA & Co-monomeric blend composition & $15.00 \mathrm{wt} . \%$ \\
\hline Camphorquinone & CQ & Sigma-Aldrich, St Louis, MO, USA & $\begin{array}{l}\text { Photo-initiator: excitation via photoactivation process and } \\
\text { reaction with } \mathrm{N}, \mathrm{N} \text {-dihydroxy ethyl-para-toluidine. }\end{array}$ & $1 \mathrm{~mol} \%$ \\
\hline $\begin{array}{l}\text { N, N-dihydroxy } \\
\text { ethyl-para-toluidine }\end{array}$ & DHEPT & Sigma-Aldrich, St Louis, MO, USA & $\begin{array}{l}\text { Co-initiator with CQ and activator with } \mathrm{BP} \text { : initiation } \\
\text { process of the polymerization reaction }\end{array}$ & $1 \mathrm{~mol} \%$ \\
\hline Benzoyl-peroxide & $\mathrm{BP}$ & Sigma-Aldrich, St Louis, MO, USA & $\begin{array}{l}\text { Initiator: initiation process of polymerization reaction with } \\
\qquad \mathrm{N}, \mathrm{N} \text {-dihydroxy ethyl-para-toluidine }\end{array}$ & $1 \mathrm{~mol} \%$ \\
\hline Nanoneedle structured zinc oxide & $\mathrm{ZnO}-\mathrm{NN}$ & Self-synthetized & $\begin{array}{c}\text { Inorganic filler: improves mechanical properties, reduces } \\
\text { hydrolytic degradation, increases viscosity, increases } \\
\text { radiopacity }\end{array}$ & * \\
\hline
\end{tabular}

* ZnO-NN was added at $0,20,30$, or $40 \mathrm{wt}$. $\%$ over the total quantity (100 \%) of the base resin (monomers and photoinitiator system) of the dental sealer, totalizing four experimental groups. 


\subsection{Flow}

The flow test was conducted in accordance with ISO 6876:2012 [27]. A total of $0.5 \mathrm{ml}$ of each experimental sealer was placed on a glass plate $(40 \times 40 \times 5 \mathrm{~mm})$ with a graduated syringe. At $180 \pm 5 \mathrm{~s}$ after the start of mixing, another plate with a mass of $20 \pm 2 \mathrm{~g}$ and a load of $100 \mathrm{~g}$ was applied on top of the material. Ten minutes after the start of mixing, the weight was removed, and the major and minor diameters of the compressed material were measured using a digital caliper. If both measurements were consistent to within $1 \mathrm{~mm}$, the results were recorded. If the major and minor diameter discs were not uniformly circular or did not match within $1 \mathrm{~mm}$, the test was repeated. For each experimental group, the test was conducted three times, and the mean value was taken.

\subsection{Film Thickness}

The film thickness evaluation was conducted following the ISO 6876:2012 [27]. Two glass plates ( $5 \mathrm{~mm}$ thick and $40 \mathrm{~mm}$ side) were placed together, and their combined thickness was measured. A drop of $0.5 \mathrm{ml}$ of the experimental sealer was placed at the center of one of the plates. Another plate was placed on top of the material. At $180 \pm 5 \mathrm{~s}$ after the start of mixing, a load of $150 \mathrm{~N}$ was applied vertically onto the top glass plate. Ten minutes after the mixing, the thickness of the two glass plates and the interposed sealer film was measured using a digital caliper. The difference in the thickness of the two glass plates, with and without a sealer, was the film thickness of the experimental sealer material. The mean value of three measurements for each sealer was taken as the film thickness of the material.

\subsection{Water Sorption and Solubility}

Water sorption and solubility tests were performed according to ISO 4049:2009 [28], except for the dimensions of the specimen $(10.0 \pm 0.1 \mathrm{~mm}$ diameter, $1.0 \pm 0.1 \mathrm{~mm}$ thickness). The samples $(\mathrm{n}=5)$ were stored in a dissector at $37^{\circ} \mathrm{C}$ containing fresh silica gel dried and maintained at $37^{\circ} \mathrm{C}$. Each sample was weighed to an accuracy of $0.01 \mathrm{mg}$ at repeated intervals of $24 \mathrm{~h}$ in an analytical balance (AUW220D, Shimadzu, Tokyo, Japan) until a constant mass $\left(m_{1}\right)$ was obtained (i.e., until the mass loss of each specimen was not more than $0.1 \mathrm{mg}$ in $24 \mathrm{~h}$ ). After final drying, two measurements of the diameter, at right angles to each other, were taken with a digital caliper, and the mean diameter was calculated. The thickness of the specimen was measured at the center of the sample and at four equally spaced points on the circumference. The area was calculated, in $\mathrm{mm}^{2}$, from the mean diameter, and then, using the mean thickness, the volume was calculated in $\mathrm{mm}^{3}$.

The samples were stored in water at $37^{\circ} \mathrm{C}$ for seven days; the volume of water for immersion was $10 \mathrm{~mL}$ per sample. Afterward, the samples were removed from the liquids, which were stored in a light-free container. Each specimen was weighed after being dried slightly to blot away the surface water, and the weight was obtained $\left(m_{2}\right)$, i.e., the mass of the hydrated samples. After weighing, the samples were returned to the first desiccator. The cycle was repeated until the constant weight was recorded as $m_{3}$. Water sorption (WS) was calculated according to Equation (1), and the solubility (SL) according to Equation (2) [29].

$$
\begin{aligned}
& \mathrm{WS}=\frac{\left(m_{2}-m_{3}\right)}{V} \\
& \mathrm{SL}=\frac{\left(m_{1}-m_{3}\right)}{V}
\end{aligned}
$$

\subsection{Radiopacity}

The radiopacity of the experimental sealers was performed according to ISO 6876:2012 [27]. Five samples per group were produced with $10.0 \mathrm{~mm}( \pm 0.1 \mathrm{~mm})$ in diameter and $1.0 \mathrm{~mm}( \pm 0.1 \mathrm{~mm})$ thick. Radiographic images were obtained using a phosphor plate digital system (VistaScan; Dürr Dental GmbH, Bietigheim-Bissingen, Germany) at $70 \mathrm{kV}$ and $8 \mathrm{~mA}$, with $0.4 \mathrm{~s}$ of exposure 
time and a focus-film distance of $400 \mathrm{~mm}$. For each film, one specimen from each concentration was positioned for a total of four samples per film. An aluminum step-wedge was exposed simultaneously with the samples in all images. The aluminum step-wedge thickness ranged from 0.5 to $5.0 \mathrm{~mm}$ in increments of $0.5 \mathrm{~mm}$ [30]. The aluminum alloy used was $\mathrm{Al} \mathrm{99.12,} \mathrm{Fe} \mathrm{0.47,} \mathrm{Mg}$ 0.41, and with $<0.1$ of $\mathrm{Cu}$ (wt.\%). The images were saved in TIFF format and analyzed using Photoshop software (Adobe Systems Incorporated, San Jose, CA, USA). The means and standard deviations of the grey levels (pixel density) of the aluminum step-wedge and the samples were obtained in a standardized area of $1.5 \mathrm{~mm}^{2}$.

\subsection{Degree of Conversion}

The degree of conversion (DC) was measured by Fourier Transform Infrared Spectroscopy (FTIR) with a spectrometer (Vertex 70, Bruker Optics, Ettinger, Germany) equipped with an attenuated total reflectance device, composed of a horizontal diamond crystal with a mirror angle of $45^{\circ}$ [31]. A light emitting diode curing unit (Radii; SDI, Bayswater, Australia) with an irradiance of $1200 \mathrm{~mW} / \mathrm{cm}^{2}$ was fixed on support to standardize the distance between the tip and the sample at $5 \mathrm{~mm}$. The sample (uncured composite) was directly dispensed $(3 \mu \mathrm{L})$ on the top of the diamond crystal and photoactivated for $60 \mathrm{~s}(\mathrm{n}=3)$. Data were evaluated with the Opus software (Bruker Optics, Ettlingen, Germany), with Blackman-Harris 3-Term apodization in a range of 4000 to $400 \mathrm{~cm}^{-1}$ and a resolution of $4 \mathrm{~cm}^{-1}$. The DC was calculated based on the intensity corresponding to the stretching of the carbon-carbon double bond (peak height) at $1635 \mathrm{~cm}^{-1}$, and a symmetric ring stretching at $1610 \mathrm{~cm}^{-1}$ of non-polymerized and polymerized samples [32]. The analyses were performed with the same samples after seven and 14 days stored at $37^{\circ} \mathrm{C}$.

\subsection{Interface Characterization by Micro-Raman}

Four lower incisor human teeth were cleaned of organic debris and stored in distilled water at $4{ }^{\circ} \mathrm{C}$. The roots were sectioned below the enamel cement junction to obtain roots with a final length of $15 \mathrm{~mm}$. The root canals were chemical-mechanically prepared with first series Kerr files until 40 files, in an ascending sequence, using a step-back technique, associated with sodium hypochlorite $1 \%$ irrigation. The canals were prepared $1 \mathrm{~mm}$ below the final strength. After the chemical mechanical preparation, the canals were irrigated with $3 \mathrm{~mL}$ EDTA for 1 minute and then washed with $3 \mathrm{~mL}$ of sodium hypochlorite and $3 \mathrm{~mL}$ of distilled water. The canals were dried with absorbent paper cones. The roots were then randomly divided and filled with the experimental sealer and gutta-percha cones as core material. The sealer was photoactivated for $40 \mathrm{~s}$ from the top of the root canal cervical portion and stored at $37 \pm 1{ }^{\circ} \mathrm{C}$ for seven days.

After this period, the roots were sectioned at low speed under constant irrigation (Low-Speed Saw, Buehler, Lake Bluff, IL, USA) perpendicular to the long axis of the root. A scan in mapping mode by Raman vibrational spectroscopy (micro Raman) was performed in line with $50 \mu \mathrm{m}$ in each slice, including sealer and dentin, so it was possible to characterize the interface and analyzed the sealer penetration into dentin. Micro-Raman spectroscopy was performed using a SENTERRA Raman Microscope (Bruker Optics, Ettlingen, Germany). It was used $785 \mathrm{~nm}$ laser for $10 \mathrm{~s}$ with five co-additions, totaling $60 \mathrm{~s}$ with $100 \mathrm{~mW}$ of laser power, resolution of $3-5 \mathrm{~cm}^{-1}$, and spectra were analyzed between 80 and $1525 \mathrm{~cm}^{-1}$.

\subsection{Antibacterial Activity}

To evaluate the antibacterial effect of the dental sealers against Enterococcus faecalis, a collection strain of this bacterium (ATCC 29212; American Type Culture Collection, Rockville, MD, USA) was used in this study. Bacteria from frozen stock cultures were grown aerobically in Brain Heart Infusion (BHI) broth (HiMedia Laboratories Pvt.Ltd, Mumbai, India) at $37^{\circ} \mathrm{C}$. Cells were harvested by centrifugation and resuspended in fresh medium. The inoculum was prepared by adjusting the cell suspension to a predetermined optical density (OD) of 0.2 at $600 \mathrm{~nm}$. 
For direct contact inhibition, three samples per group were produced with $3 \mathrm{~mm}( \pm 0.1 \mathrm{~mm})$ in diameter and $1.0 \mathrm{~mm}( \pm 0.1 \mathrm{~mm})$ thick. The samples were sterilized in hydrogen peroxide plasma. Using a 96-well flat-bottom plate, each specimen was placed on a well containing $300 \mu \mathrm{L}$ BHI broth (HiMedia Laboratories Pvt. Ltd, Mumbai, India). Then, each well was inoculated with $20 \mu \mathrm{L}$ of the E. faecalis suspension. The negative control consisted of three sets of wells containing uninoculated fresh medium $(300 \mu \mathrm{L})$.

Immediately after the placement of inoculums and after $24 \mathrm{~h}, 90 \mu \mathrm{L}$ of each well content was diluted in saline to $10^{-8}$. The $10^{-1}, 10^{-3}, 10^{-6}$, and $10^{-8}$ dilutions were plated in BHI Agar (HiMedia Laboratories), using $25 \mu \mathrm{L}$ aliquots of each dilution in duplicate. Plates were incubated at $37^{\circ} \mathrm{C}$ under anaerobic conditions. After $24 \mathrm{~h}$, the colonies were counted visually, scaled by dilution factors, and then expressed as colony-forming units (CFUs) per milliliters. The groups were statistically compared to each other. The experiment was carried out under aseptic conditions.

\subsection{Statistical Analysis}

Data of radiopacity, flow, film thickness, water sorption, and solubility were analyzed using one-way ANOVA and Tukey. The antibacterial analysis was analyzed via two-way ANOVA (concentration of $\mathrm{ZnO}-\mathrm{NN}$ and time) and the Student Newman Keuls test. Repeated-measures ANOVA and Tukey analyzed the DC data. All analyses were performed at 0.05 level of significance.

\section{Results}

Figure 2 shows the SEM images that revealed sharply tapered needle-shaped zinc oxide arms radiating from the center in dense distribution. The mean diameter of the $\mathrm{ZnO}$ needles was approximately $40 \mathrm{~nm}$. The surface area by the Brunauer-Emmett-Teller (BET) method showed $16 \mathrm{~m}^{2} / \mathrm{g}$ for the $\mathrm{ZnO}-\mathrm{NN}$.

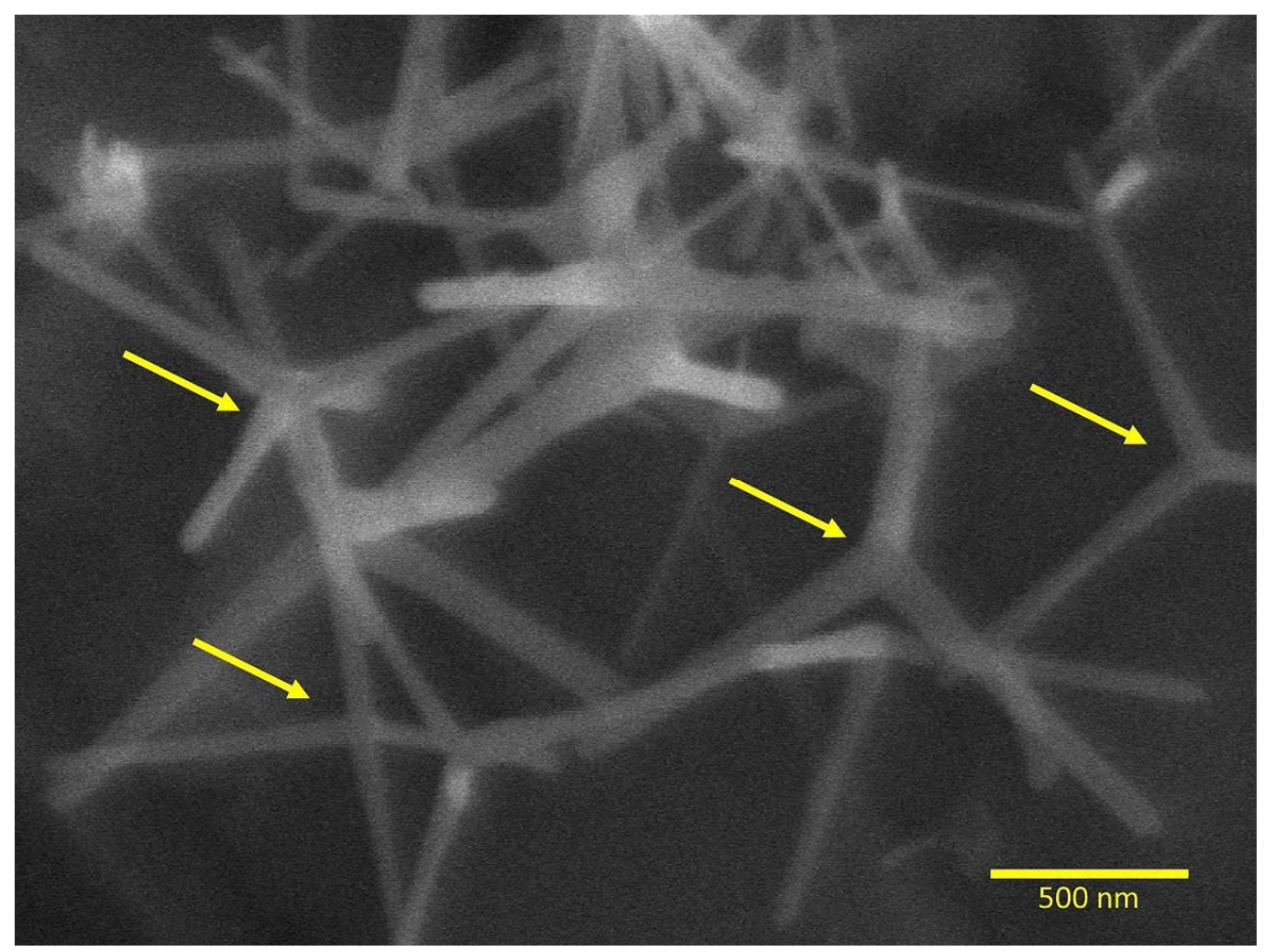

Figure 2. Scanning electron microscopy of $\mathrm{ZnO}-\mathrm{NN}$ showing the nanostructure after the thermal evaporation process (magnification of 40,000 $\times$ ). The arrows indicate the nucleation core that originates the extensions with distinct directions within three-dimensional space. 
The flow and film thickness values are displayed in Table 2. The flow of the experimental dental sealer without $\mathrm{ZnO}-\mathrm{NN}$ addition was unable to measure due to the lack of filler addition, high flowability, so it exceeded the plate limits. The flow of the groups containing $\mathrm{ZnO}-\mathrm{NN}$ ranged from $17.2( \pm 2.1) \mathrm{mm}$ for $40 \mathrm{wt} . \%$ of $\mathrm{ZnO}-\mathrm{NN}$ to $18.6( \pm 1.0) \mathrm{mm}$ for $20 \mathrm{wt} . \%$ of $\mathrm{ZnO}-\mathrm{NN}$, without statistical difference among groups $(p>0.05)$. The film thickness ranged from $26.7( \pm 5.0) \mathrm{mm}$ for $0 \mathrm{wt} . \%$ to $56.7( \pm 5.8) \mathrm{mm}$ for $40 \mathrm{wt} . \%$ of $\mathrm{ZnO}-\mathrm{NN}$. The groups containing $\mathrm{ZnO}-\mathrm{NN}$ showed higher film thickness in comparison to $0 \mathrm{wt} . \%(p<0.05)$ without statistical difference among the three concentrations of $\mathrm{ZnO}-\mathrm{NN}(p>0.5)$.

Table 2. Mean and standard deviation (within bracket) values of flow, film thickness, water sorption, and solubility, $\mathrm{pH}$, and radiopacity of the dental sealers.

\begin{tabular}{cccccc}
\hline Groups & Flow $(\mathbf{m m})$ & Film Thickness $(\mathbf{m m})$ & $\begin{array}{c}\text { Water Sorption } \\
(\mu \mathbf{m} / \mathbf{m m}))\end{array}$ & $\begin{array}{c}\text { Solubility } \\
(\mu \mathbf{m} / \mathbf{m m})\end{array}$ & $\begin{array}{c}\text { Radiopacity } \\
\text { (pixels) }\end{array}$ \\
\hline $0 \%$ & $*$ & $26.7( \pm 5.0)^{\mathrm{B}}$ & $39.4( \pm 5.6)^{\mathrm{A}}$ & $-4.2( \pm 0.1)^{\mathrm{A}}$ & $66.8( \pm 5.3)^{\mathrm{C}}$ \\
$20 \%$ & $19.8( \pm 1.0)^{\mathrm{A}}$ & $54.0( \pm 12.2)^{\mathrm{A}}$ & $32.3( \pm 1.7)^{\mathrm{A}}$ & $-3.0( \pm 1.4)^{\mathrm{A}}$ & $103.6( \pm 6.9)^{\mathrm{B}}$ \\
$30 \%$ & $18.6( \pm 1.0)^{\mathrm{A}}$ & $48.0( \pm 7.2)^{\mathrm{A}}$ & $35.2( \pm 3.8)^{\mathrm{A}}$ & $-1.7( \pm 1.5)^{\mathrm{A}}$ & $110.6( \pm 7.9)^{\mathrm{A}, \mathrm{B}}$ \\
$40 \%$ & $17.2( \pm 2.0)^{\mathrm{A}}$ & $56.7( \pm 5.8)^{\mathrm{A}}$ & $36.5( \pm 6.5)^{\mathrm{A}}$ & $0.3( \pm 6.1)^{\mathrm{A}}$ & $123.2( \pm 9.0)^{\mathrm{A}, \#}$ \\
\hline
\end{tabular}

* Flow of experimental sealer without $\mathrm{ZnO}-\mathrm{NN}$ addition was unable to measure. \# The group with $40 \mathrm{wt} \%$ of ZnO-NN showed no statistical difference for $1 \mathrm{~mm}$ of aluminum $(p>0.05)$. Different capital letters indicate statistically significant differences in the same column $(p<0.05)$.

Table 2 also displays the results of water sorption and solubility analyses. There was no statistically significant difference among groups in both tests $(p>0.05)$. The radiopacity of the dental sealers ranged from $66.8( \pm 5.3)$ pixels to $0 \mathrm{wt} . \%$ to $123.2( \pm 9.0)$ pixels to $40 \mathrm{wt} . \%$ of $\mathrm{ZnO}-\mathrm{NN}$. By increasing the concentration of $\mathrm{ZnO}-\mathrm{NN}$ addition, the higher the radiopacity, with no differences comparing 30 and $40 \mathrm{wt} . \%$ of $\mathrm{ZnO}-\mathrm{NN}(p>0.05)$. The group containing $40 \mathrm{wt} . \%$ of $\mathrm{ZnO}-\mathrm{NN}$ showed no difference from the $1 \mathrm{~mm}$ of aluminum $(p>0.05)$.

Table 3 displays the DC of all groups immediately, seven, and 14 days after the manipulation and photoactivation of the dental sealers. Shortly after the photoactivation, the group containing $20 \mathrm{wt} . \%$ of $\mathrm{ZnO}-\mathrm{NN}$ showed no difference in comparison to the group without $\mathrm{ZnO}-\mathrm{NN}$ addition $(p>0.05)$. Over time, the group containing 40 wt. \% of $\mathrm{ZnO}-\mathrm{NN}$ increased its $\mathrm{DC}$ from $2.4( \pm 1.2) \%$ to $25.9( \pm 3.4)$ $\%$ after 14 days of storage $(p<0.05)$.

Table 3. Mean and standard deviation (within bracket) values of degree of conversion (\%) of the dental sealers immediately, seven, and 14 days after the photoactivation.

\begin{tabular}{cccc}
\hline Groups & Immediate & 7 Days & 14 Days \\
\hline $\mathbf{0 \%}$ & $49.9( \pm 0.4)^{\mathrm{A}, \mathrm{a}}$ & $48.1( \pm 1.3)^{\mathrm{A}, \mathrm{a}}$ & $48.1( \pm 0.4)^{\mathrm{A}, \mathrm{a}}$ \\
$\mathbf{2 0} \%$ & $46.2( \pm 1.5)^{\mathrm{A}, \mathrm{B}, \mathrm{a}}$ & $38.1( \pm 2.8)^{\mathrm{B}, \mathrm{b}}$ & $32.5( \pm 2.3)^{\mathrm{B}, \mathrm{b}}$ \\
$\mathbf{3 0 \%}$ & $43.0( \pm 2.4)^{\mathrm{B}, \mathrm{a}}$ & $30.0( \pm 3.0)^{\mathrm{C}, \mathrm{b}}$ & $31.5( \pm 2.8)^{\mathrm{B}, \mathrm{b}}$ \\
$\mathbf{4 0 \%}$ & $2.4( \pm 1.2)^{\mathrm{C}, \mathrm{b}}$ & $26.7( \pm 4.6)^{\mathrm{D}, \mathrm{a}}$ & $25.9( \pm 3.4)^{\mathrm{C}, \mathrm{a}}$ \\
\hline
\end{tabular}

Different capital letters indicate statistically significant differences in the same column $(p<0.05)$. Different small letters indicate significant differences in the same line $(p<0.05)$.

Figure 3 shows the micro-Raman results from the analysis of the dental- sealer interface in the root canal. Along with the interface, from the sealer to the dentin, there is a decreased high of $\mathrm{ZnO}$ peak and an increase in the peak related to phosphate. The existence of an area in the interface with peaks from $\mathrm{ZnO}$ and phosphate suggests that $\mathrm{ZnO}$ was in close contact with dentin and may have penetrated the dentinal tubules. 
(a)

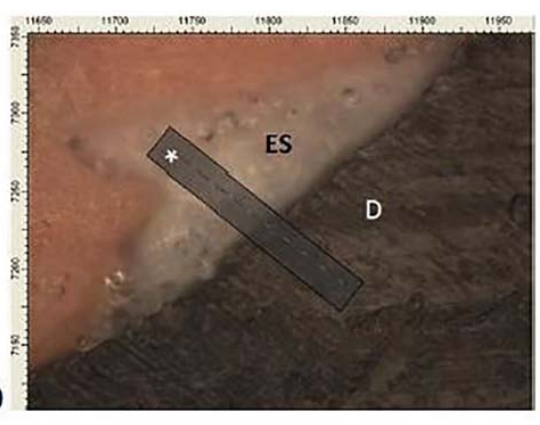

(c)

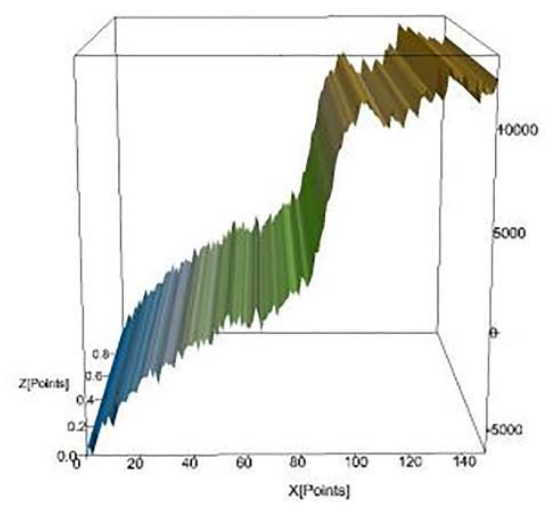

(b)

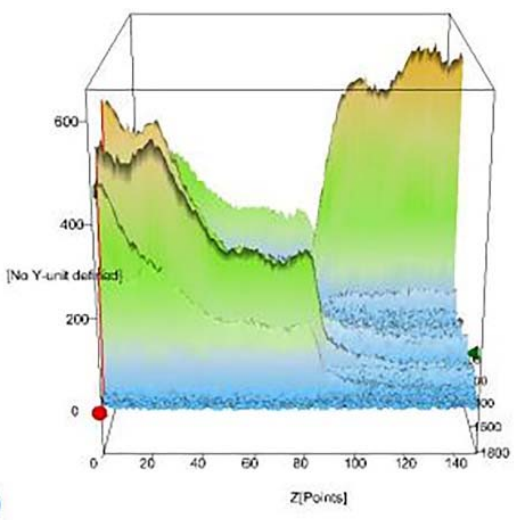

(d)

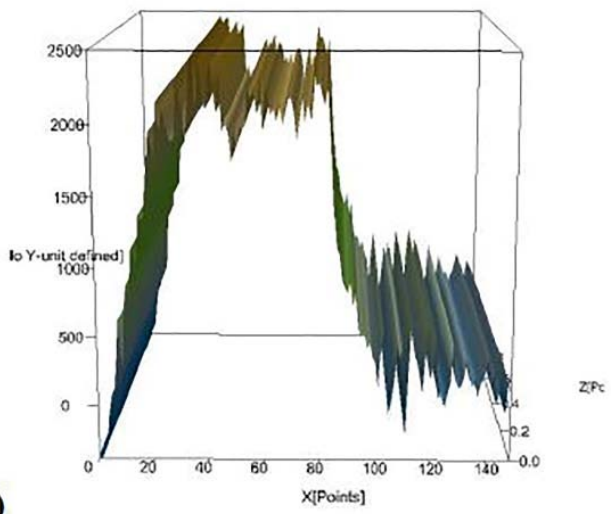

Figure 3. Representative micro-Raman analysis at the dentin-sealer interface. Image (a) represents the interface dentin-sealer, where ES states for experimental sealer, D states for dentine, and * is the analyzed line at the interface. Image (b) represents the total interface area. Image (c) displays the graph when there is integration in micro-Raman analysis for the hydroxyapatite (HAp) using the peak at $910 \mathrm{~cm}^{-1}$. Image (d) shows the graph when there is integration in the micro-Raman study for $\mathrm{ZnO}$ using the peak at $582 \mathrm{~cm}^{-1}$. Note that from the sealer analysis into dentin, there is a decrease in the $\mathrm{ZnO}$ peak and an increase in the phosphate peak contained in hydroxyapatite (HAp). There is a site in the center of the interface (image $\mathbf{b}$ ) where there is still a high peak of phosphate and the maintenance of the $\mathrm{ZnO}$ peak. The overlap of graphs (c,d) shows the presence of $\mathrm{ZnO}$ and phosphate in the same site, suggesting that the $\mathrm{ZnO}$ was able to penetrate the dentinal tubules.

Figure 4 displays the results of the antibacterial analysis. Immediately after the inoculum, there were no differences among groups $(p>0.05)$. After $24 \mathrm{~h}$ of contact with the sealers, the groups with $\mathrm{ZnO}-\mathrm{NN}$ addition showed a reduced number of bacterial viability when compared to the group without $\mathrm{ZnO}-\mathrm{NN}(p<0.05)$. At this period, the results ranged from $9.2( \pm 0.0) \log _{10} \mathrm{CFU}$ for $0 \%$ of $\mathrm{ZnO}-\mathrm{NN}$ to $8.3( \pm 0.2) \log _{10} \mathrm{CFU}$ for the group with $20 \mathrm{wt}$ \% of $\mathrm{ZnO}-\mathrm{NN}(p<0.05)$. The groups with 20 to $40 \mathrm{wt}$ \% of $\mathrm{ZnO}-\mathrm{NN}$ showed no differences among them $(p>0.05)$. 


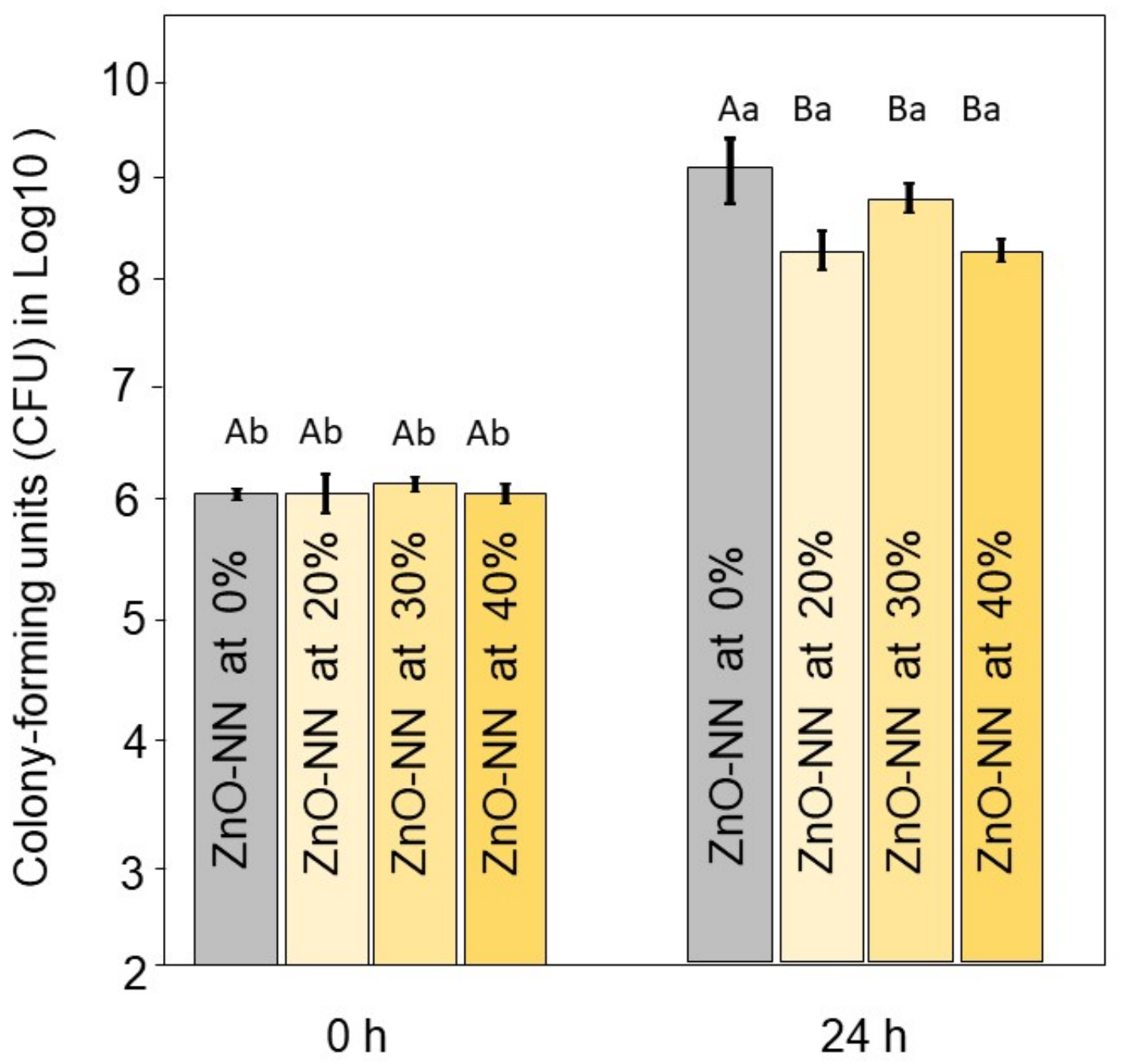

Figure 4. Results of antibacterial analysis of the resin sealers. Mean and standard deviation values of colony-forming units (CFU) in $\log _{10}$ at 0 and $24 \mathrm{~h}$ of the experimental dental sealers against E. faecalis. Different capital letters indicate significant differences among groups within the same time $(p<0.05)$. Different small letters indicate significant differences within the same group at different times $(p<0.05)$.

\section{Discussion}

In the present study, needle-like zinc oxide nanostructures (ZnO-NN) were explored as inorganic fillers to improve dental resin sealers. ZnO-NN was successfully synthesized and incorporated in an experimental methacrylate-based root canal sealer. $\mathrm{ZnO}-\mathrm{NN}$ addition to the sealer increased its radiopacity, maintaining reliable film thickness, flow, $\mathrm{pH}$, and proving activity against $E$. faecalis.

The success of endodontic therapy depends on a complete root canal filling to promote adequate sealing [22]. The sealer should present sufficiently flow to penetrate the irregularities and ramifications of the root canal system to encourage a complete obliteration. The filler size can influence flow and film thickness [33]. The reduction of particle size to nano-range increases the surface area, e.g., $16 \mathrm{~m}^{2} / \mathrm{g}$ of surface area in this study, decreasing the volume fraction that could be added to the polymeric matrix. In the present study, nanosized particles (mean needle diameter of $40 \mathrm{~nm}$ ) of $\mathrm{ZnO}$ were produced and used for sealer formulation. The $\mathrm{ZnO}-\mathrm{NN}$ addition adjusted the viscosity of the sealer, considering that the group without nanoparticle addition showed a flow that could not be measured (i.e., material flowed beyond the glass plate). One could think that a sealer should present a low viscosity; however, sealers with a high flow could overflow beyond the apex leading to 
biocompatibility concerns. The $\mathrm{ZnO}-\mathrm{NN}$ addition improved the handling of the material to be used as an endodontic sealer.

Despite better handling, the materials proposed with $\mathrm{ZnO}-\mathrm{NN}$ showed flow above $17 \mathrm{~mm}$ even with the addition of $40 \mathrm{wt} . \%$, which is following the requirements of ISO 6876:2012 [27]. The film thickness increased with the addition of $\mathrm{ZnO}-\mathrm{NN}$ (Table 2). However, there was no difference from 20 to $40 \mathrm{wt} . \%$ of $\mathrm{ZnO}-\mathrm{NN}(p>0.05)$. The values found for flow and film thickness were similar to the ones established at ISO 6876:2012 [27] (more than $17 \mathrm{~mm}$ and less than $50 \mu \mathrm{m}$, respectively). The materials here proposed are probably prone to achieve the apical foramen of dental roots and penetrate under challenging sites in root dentin such as accessory canals, supporting the endodontic treatments.

The wettability of dentin may interfere in the polymeric network formation leading to a resin more prone to long term degradation. It is well known that methacrylate-based materials can present hydrolytic degradation over time in the oral environment [34]. The water sorption and solubility of the polymer could lead to a variety of chemical and physical processes, resulting in harmful effects on the structure and function of dental polymers. These materials can suffer a swelling process [35], and, after swelling, the leaching of unreacted monomers may occur, affecting their stability [36]. Therefore, the experimental materials must not show higher sorption and solubility when in contact with wet environments. In the current study, water sorption and solubility values showed no statistical difference among groups. Lack of solubility has also been stated as an ideal characteristic of root canal filling materials [22] to prevent inflammatory processes in the apical region [23].

Low water sorption and solubility can be achieved with the assistance of a suitable DC of carbon-carbon double bonds into carbon-carbon single bonds [37]. A high DC may lead to low solubility, decreasing the amount of unreacted monomer into the polymeric matrix. Moreover, the increased DC is related to improved mechanical properties [38]. The groups with 20 and $30 \mathrm{wt} . \%$ of $\mathrm{ZnO}-\mathrm{NN}$ showed higher DC than $40 \mathrm{wt} . \%$. The reason for that is probably related to the decrease of light energy available within the polymer because it depends on the refractive index of the filler incorporated and the final opacity of the resin-filler composition [39,40]. However, this group with higher $\mathrm{ZnO}$ concentration had increased DC overtime after being stored at $37^{\circ} \mathrm{C}$ due to the dual-cure system added to the sealers. Overall, all materials presented reliable DC, similar to commercial sealers [41].

Another relevant aspect for sealers is the achievement of radiopacity to make possible the differentiation of the material from the adjacent anatomical structures [30]. ISO 6876:2012 establishes $3 \mathrm{~mm}$ of aluminum as the desired radiopacity value for materials to be used as endodontic sealers. The addition of $\mathrm{ZnO}-\mathrm{NN}$ in all concentrations did not achieve this value. Although the experimental sealers did not meet the ISO requirements, $20 \mathrm{wt} . \%$ addition showed higher values than the control group $(p<0.05)$. Moreover, with $40 \mathrm{wt} . \%$ of $\mathrm{ZnO}-\mathrm{NN}$, the sealers achieved radiopacity compatible with $1 \mathrm{~mm}$ of aluminum. Therefore, further modification in the sealer's composition via the incorporation of radiopacifying agents, i.e., bismuth oxide or ytterbium trifluoride [42], could be performed to surpass their clinical applicability.

The micro-Raman spectra of the sealer/dentin interface suggested the penetration of ZnO-NN into the root canal dentin. The presence of inorganic filler into the dentinal tubules may improve the stability of dentin-methacrylate material interface [43]. Besides, $\mathrm{ZnO}-\mathrm{NN}$ infiltration into dentin could assist in decreasing collagen degradation by reducing matrix metalloproteinases expression [44] and provide bioactivity for dentin tissue [10].

It is already well established that even after the root canal preparation for endodontic treatment with complete irrigation and shaping, there are still microorganisms on the root canal walls [45]. The improvement of the biological properties of root canal sealers has been studied to overcome this issue $[46,47]$. The dentinal tubule infection may lead to recurrent disease, determining endodontic retreatment [48]. Here, all concentrations of $\mathrm{ZnO}-\mathrm{NN}$ addition $(20,30$, or $40 \mathrm{wt} . \%)$ affected the E. faecalis growth assessed by direct contact inhibition. 
In the literature, the mechanisms of antibacterial activity of nanostructured $\mathrm{ZnO}$ are not well understood, although some statements were proposed, such as the generation of hydrogen peroxide could be the main factor of antibacterial activity [49]. Tiwari's group have proposed a mechanism of action of $\mathrm{ZnO}$ involving the production of reactive oxygen species, which elevates membrane lipid peroxidation that causes membrane leakage of reducing sugars, proteins, DNA, and reduces cell viability [50]. There is also sequential oxidation-reduction reactions, which occur on the $\mathrm{ZnO}$ particle surface to produce reactive species such as hydrogen peroxide $\left(\mathrm{H}_{2} \mathrm{O}_{2}\right)$ and hydroxyl radicals. The reactive oxygen species (ROS) might trigger membrane lipid peroxidation and cause an antibacterial effect.

Some microorganisms escape oxidative stress by living in anaerobic microhabitats; all others must deal with the consequences of intracellular $\mathrm{O}_{2}$ [51]. However, almost all of these microorganisms suffer poor growth, elevated mutagenesis, or even death when they are exposed to $\mathrm{O}_{2}$ levels that exceed those of their native habitats [52]. E. faecalis represents an important clinical problem due to virulence factors such as the regulation of the oxidative stress response by transcriptional regulation by estrogen receptors [53]. A number of antioxidative enzymes have been identified in E. faecalis confer protection against hydrogen peroxide, hydroxyl radicals, and superoxide. The defense against other reactive oxygen or nitrogen species is indirect or nonenzymatic.

The use of sealer exhibiting antibacterial properties may be useful to decrease or avoid the growth of the remaining microorganisms in the endodontic system [54]. E. faecalis is a recognized pathogen in post-treatment endodontic infections, and it is considered the most resistant species against chemomechanical preparation [55]. Considering the demonstrated potential antimicrobial effect of $\mathrm{ZnO}-\mathrm{NN}$ and the size-dependent characteristic of this effect, these small particles may contribute to dentin tubules' disinfection. Usually, the endodontic proposed materials are tested against E. faecalis due to the reasons described above. Here, we have estimated the antibacterial activity of sealers containing $\mathrm{ZnO}-\mathrm{NN}$ using a relevant single-species model. The clinical predictive value of in vitro tests is currently often limited. In this study, even though we observed statistical difference in comparison to $0 \mathrm{wt} . \%$ of $\mathrm{ZnO}-\mathrm{NN}$, there was no substantial $\log$ reduction. The reason for that may be because the test was conducted against planktonic bacteria. Therefore, the leaching of more $\mathrm{ZnO}-\mathrm{NN}$ to the broth containing E. faecalis would be necessary to increase the differences. After $24 \mathrm{~h}$, the material was probably stable enough not to provide a high quantity of free $\mathrm{Zn}+$.

For this reason, further studies could be carried out to understand the effects of the sealers containing $\mathrm{ZnO}-\mathrm{NN}$ against multi-species biofilm over time. These investigations can be a promising next step to translate the experimental dental sealers containing $\mathrm{ZnO}-\mathrm{NN}$ into clinical settings.

\section{Conclusions}

In this work, we explored the applicability of $\mathrm{ZnO}-\mathrm{NN}$ incorporated in an experimental methacrylate-based root canal sealer to impart improved properties. Overall, the incorporation of $\mathrm{ZnO}-\mathrm{NN}$ provided an antibacterial effect without a significant detrimental impact on the physical and chemical functionality of the material. The use of $\mathrm{ZnO}-\mathrm{NN}$ as inorganic filler is a potential application within dental materials intended for root canal treatment.

Author Contributions: Conceptualization, F.M.C., S.M.W.S., and V.C.B.L.; Formal analysis, F.M.C. and V.C.B.L.; Investigation, F.M.C., V.C.B.L., M.K., C.F.P., F.A.L.S., A.T., and C.P.B.; Supervision, F.M.C., V.C.B.L., S.M.W.S.; Writing-Original Draft Preparation, F.M.C., I.M.G., M.A.M.; Writing—Review \& Editing, M.A.M. All authors have read and agreed to the published version of the manuscript.

Funding: This research received no external funding.

Acknowledgments: The authors gratefully acknowledge the agency Fundação de Amparo à Pesquisa do Estado do Rio Grande do Sul (FAPERGS, Brazil) for the scholarship of MK. This study was financed in part by the Coordenação de Aperfeiçoamento de Pessoal de Nível Superior-Brasil (CAPES)—Finance Code 001 (scholarship of IMG).

Conflicts of Interest: The authors declare no conflict of interest. 


\section{References}

1. Raghupathi, K.R.; Koodali, R.T.; Manna, A.C. Size-dependent bacterial growth inhibition and mechanism of antibacterial activity of zinc oxide nanoparticles. Langmuir 2011, 27, 4020-4028. [CrossRef]

2. Roduner, E. Size matters: Why nanomaterials are different. Chem. Soc. Rev. 2006, 35, 583-592. [CrossRef] [PubMed]

3. Melo, M.A.S.; Guedes, S.F.F.; Xu, H.H.K.; Rodrigues, L.K.A. Nanotechnology-based restorative materials for dental caries management. Trends Biotechnol. 2013, 31, 459-467. [CrossRef] [PubMed]

4. Hume, W.R. The pharmacologic and toxicological properties of zinc oxide-eugenol. J. Am. Dent. Assoc. 1986, 113, 789-791. [CrossRef] [PubMed]

5. Markowitz, K.; Moynihan, M.; Liu, M.; Kim, S. Biologic properties of eugenol and zinc oxide-eugenol: A clinically oriented review. Oral Surg. Oral Med. Oral Pathol. Oral Radiol. 1992, 73, 729-737. [CrossRef]

6. Niu, L.N.; Fang, M.; Jiao, K.; Tang, L.H.; Xiao, Y.H.; Shen, L.J.; Chen, J.H. Tetrapod-like zinc oxide whisker enhancement of resin composite. J. Dent. Res. 2010, 89, 746-750. [CrossRef] [PubMed]

7. Garcia, I.M.; Leitune, V.C.B.; Kist, T.L.; Takimi, A.; Samuel, S.M.W.; Collares, F.M. Quantum dots as nonagglomerated nanofillers for adhesive resins. J. Dent. Res. 2016, 95, 1401-1407. [CrossRef] [PubMed]

8. Garcia, I.M.; Leitune, V.C.B.; Visioli, F.; Samuel, S.M.W.; Collares, F.M. Influence of zinc oxide quantum dots in the antibacterial activity and cytotoxicity of an experimental adhesive resin. J. Dent. 2018, 73, 57-60. [CrossRef]

9. Divya, M.; Vaseeharan, B.; Abinaya, M.; Vijayakumar, S.; Govindarajan, M.; Alharbi, N.S.; Kadaikunnan, S.; Khaled, J.M.; Benelli, G. Biopolymer gelatin-coated zinc oxide nanoparticles showed high antibacterial, antibiofilm and anti-angiogenic activity. J. Photochem. Photobiol. B Biol. 2018, 178, 211-218. [CrossRef]

10. Osorio, R.; Cabello, I.; Toledano, M. Bioactivity of zinc-doped dental adhesives. J. Dent. 2014, 42, 403-412. [CrossRef]

11. Cheng, L.; Zhang, K.; Weir, M.D.; Melo, M.A.S.; Zhou, X.; Xu, H.H.K. Nanotechnology strategies for antibacterial and remineralizing composites and adhesives to tackle dental caries. Nanomedicine 2015, 10, 627-641. [CrossRef] [PubMed]

12. Balhaddad, A.A.; Kansara, A.A.; Hidan, D.; Weir, M.D.; Xu, H.H.K.; Melo, M.A.S. Toward dental caries: Exploring nanoparticle-based platforms and calcium phosphate compounds for dental restorative materials. Bioact. Mater. 2019, 4, 43-55. [CrossRef] [PubMed]

13. Chao, L.-C.; Lee, J.-W.; Liau, C.-C. ZnO nanoneedles prepared by ion implantation and thermal oxidation on metallic zinc foils. J. Phys. D Appl. Phys. 2008, 41, 115405. [CrossRef]

14. Park, D.; Tak, Y.; Yong, K. Fabrication and characterization of $\mathrm{ZnO}$ nanoneedle array using metal organic chemical vapor deposition. J. Nanosci. Nanotechnol. 2008, 8, 623-627. [CrossRef]

15. Kumari, P.; Roy, S.S.; McLaughlin, J. Growth and characterization of zinc oxide nanoneedles. J. Nanosci. Nanotechnol. 2009, 9, 4367-4370. [CrossRef]

16. Kim, T.Y.; Lee, S.H.; Mo, Y.H.; Nahm, K.S.; Kim, J.Y.; Sun, E.K.; Kim, M. Growth mechanism of needle-shaped $\mathrm{ZnO}$ nanostructures over NiO-coated Si substrates. Korean J. Chem. Eng. 2004, 21, 733-738. [CrossRef]

17. Neykova, N.; Brož, A.; Remeš, Z.; Hruška, K.; Kalbáčová, M.; Kromka, A.; Vaněček, M. ZnO hedgehog-like structures for control cell cultivation. Appl. Surf. Sci. 2012, 258, 3485-3489. [CrossRef]

18. Jones, N.; Ray, B.; Ranjit, K.T.; Manna, A.C. Antibacterial activity of ZnO nanoparticle suspensions on a broad spectrum of microorganisms. FEMS Microbiol. Lett. 2008, 279, 71-76. [CrossRef]

19. Zhong, L.; Liu, H.; Samal, M.; Yun, K. Synthesis of ZnO nanoparticles-decorated spindle-shaped graphene oxide for application in synergistic antibacterial activity. J. Photochem. Photobiol. B Biol. 2018, 183, $293-301$. [CrossRef]

20. Stuart, C.H.; Schwartz, S.A.; Beeson, T.J.; Owatz, C.B. Enterococcus faecalis: Its role in root canal treatment failure and current concepts in retreatment. J. Endod. 2006, 32, 93-98. [CrossRef]

21. Partoazar, A.; Talaei, N.; Bahador, A.; Pourhajibagher, M.; Dehpour, S.; Sadati, M.; Bakhtiarian, A. Antibiofilm activity of natural zeolite supported NanoZnO: Inhibition of Esp gene expression of Enterococcus faecalis. Nanomedicine 2019, 14, 675-687. [CrossRef] [PubMed]

22. AlShwaimi, E.; Bogari, D.; Ajaj, R.; Al-Shahrani, S.; Almas, K.; Majeed, A. In vitro antimicrobial effectiveness of root canal sealers against enterococcus faecalis: A systematic review. J. Endod. 2016, 42, 1588-1597. [CrossRef] [PubMed] 
23. Fonseca, D.A.; Paula, A.B.; Marto, C.M.; Coelho, A.; Paulo, S.; Martinho, J.P.; Carrilho, E.; Ferreira, M.M. Biocompatibility of root canal sealers: A systematic review of in vitro and in vivo studies. Materials 2019, 12, 4113. [CrossRef] [PubMed]

24. Jin, X.; Deng, M.; Kaps, S.; Zhu, X.; Hölken, I.; Mess, K.; Adelung, R.; Mishra, Y.K. Study of tetrapodal ZnO-PDMS composites: A comparison of fillers shapes in stiffness and hydrophobicity improvements. PLoS ONE 2014, 9, e106991. [CrossRef]

25. Leitune, V.C.B.; Schiroky, P.R.; Genari, B.; Camassola, M.; S, F.A.L.; Samuel, S.M.W.; Collares, F.M. Nanoneedle-like zinc oxide as a filler particle for an experimental adhesive resin. Indian J. Dent. Res. 2019, 30, 777-782.

26. Yao, B.D.; Chan, Y.F.; Wang, N. Formation of $\mathrm{ZnO}$ nanostructures by a simple way of thermal evaporation. Appl. Phys. Lett. 2002, 81, 757-759. [CrossRef]

27. International Organization for Standardization. ISO 6876:2012—Dentistry—Root Canal Sealing Materials; International Organization for Standardization: Geneva, Switzerland, 2012; pp. 1-9.

28. International Organization for Standardization. ISO 4049:2009_Dentistry-Polymer-Based Restorative Materials; International Organization for Standardization: Geneva, Switzerland, 2009; pp. 1-28.

29. Collares, F.M.; Ogliari, F.A.; Zanchi, C.H.; Petzhold, C.L.; Piva, E.; Samuel, S.M.W. Influence of 2-hydroxyethyl methacrylate concentration on polymer network of adhesive resin. J. Adhes. Dent. 2011, 13, 125-129.

30. Garcia, I.M.; Leitune, V.C.B.; Takimi, A.S.; Bergmann, C.P.; Samuel, S.M.W.; Melo, M.A.; Collares, F.M. Cerium dioxide particles to tune radiopacity of dental adhesives: Microstructural and physico-chemical evaluation. J. Funct. Biomater. 2020, 11, 7. [CrossRef]

31. Maktabi, H.; Ibrahim, M.; Alkhubaizi, Q.; Weir, M.; Xu, H.; Strassler, H.; Fugolin, A.P.P.; Pfeifer, C.S.; Melo, M.A.S. Underperforming light curing procedures trigger detrimental irradiance-dependent biofilm response on incrementally placed dental composites. J. Dent. 2019, 88, 103110. [CrossRef]

32. Collares, F.M.; Portella, F.F.; Leitune, V.C.B.; Samuel, S.M.W. Discrepancies in degree of conversion measurements by FTIR. Braz. Oral Res. 2013, 27, 453-454.

33. De Souza, M.O.; Branco Leitune, V.C.; Bohn, P.V.; Werner Samuel, S.M.; Collares, F.M. Physical-mechanical properties of Bis-EMA based root canal sealer with different fillers addition. J. Conserv. Dent. 2015, 18, 227-231.

34. Ferracane, J.L. Hygroscopic and hydrolytic effects in dental polymer networks. Dent. Mater. 2006, 22, 211-222. [CrossRef] [PubMed]

35. Ersahan, S.; Aydin, C. Solubility and apical sealing characteristics of a new calcium silicate-based root canal sealer in comparison to calcium hydroxide-, methacrylate resin- and epoxy resin-based sealers. Acta Odontol. Scand. 2013, 71, 857-862. [CrossRef] [PubMed]

36. Donnelly, A.; Sword, J.; Nishitani, Y.; Yoshiyama, M.; Agee, K.; Tay, F.R.; Pashley, D.H. Water sorption and solubility of methacrylate resin-based root canal sealers. J. Endod. 2007, 33, 990-994. [CrossRef] [PubMed]

37. Durner, J.; Obermaier, J.; Draenert, M.; Ilie, N. Correlation of the degree of conversion with the amount of elutable substances in nano-hybrid dental composites. Dent. Mater. 2012, 28, 1146-1153. [CrossRef]

38. Hass, V.; Dobrovolski, M.; Zander-Grande, C.; Martins, G.C.; Gordillo, L.A.A.; Rodrigues Accorinte, M.D.L.; Gomes, O.M.M.; Loguercio, A.D.; Reis, A. Correlation between degree of conversion, resin-dentin bond strength and nanoleakage of simplified etch-and-rinse adhesives. Dent. Mater. 2013, 29, 921-928. [CrossRef] [PubMed]

39. Garcia, I.M.; Leitune, V.C.B.; Ferreira, C.J.; Collares, F.M. Tantalum oxide as filler for dental adhesive resin. Dent. Mater. J. 2018, 37, 897-903. [CrossRef]

40. Leitune, V.C.B.; Collares, F.M.; Takimi, A.; de Lima, G.B.; Petzhold, C.L.; Bergmann, C.P.; Samuel, S.M.W. Niobium pentoxide as a novel filler for dental adhesive resin. J. Dent. 2013, 41, 106-113. [CrossRef]

41. Beriat, N.C.; Ertan, A.; Cehreli, Z.C.; Gulsahi, K. Time-dependent conversion of a methacrylate-based sealer polymerized with different light-curing units. J. Endod. 2009, 35, 110-112. [CrossRef]

42. Collares, F.M.; Klein, M.; Santos, P.D.; Portella, F.F.; Ogliari, F.; Leitune, V.C.B.; Samuel, S.M.W. Influence of radiopaque fillers on physicochemical properties of a model epoxy resin-based root canal sealer. J. Appl. Oral Sci. 2013, 21, 533-539. [CrossRef]

43. Toledano, M.; Yamauti, M.; Ruiz-Requena, M.E.; Osorio, R. A ZnO-doped adhesive reduced collagen degradation favouring dentine remineralization. J. Dent. 2012, 40, 756-765. [CrossRef] [PubMed] 
44. Osorio, R.; Osorio, E.; Medina-Castillo, A.L.; Toledano, M. Polymer nanocarriers for dentin adhesion. J. Dent. Res. 2014, 93, 1258-1263. [CrossRef] [PubMed]

45. Kirsch, J.; Basche, S.; Neunzehn, J.; Dede, M.; Dannemann, M.; Hannig, C.; Weber, M.-T. Is it really penetration? Locomotion of devitalized Enterococcus faecalis cells within dentinal tubules of bovine teeth. Arch. Oral Biol. 2017, 83, 289-296. [CrossRef] [PubMed]

46. Monteiro, J.C.; Garcia, I.M.; Leitune, V.C.B.; Visioli, F.; de Souza Balbinot, G.; Samuel, S.M.W.; Makeeva, I.; Collares, F.M.; Sauro, S. Halloysite nanotubes loaded with alkyl trimethyl ammonium bromide as antibacterial agent for root canal sealers. Dent. Mater. 2019, 35, 789-796. [CrossRef] [PubMed]

47. Rostirolla, F.V.; Leitune, V.C.B.; Bohns, F.R.; Portella, F.F.; Samuel, S.M.W.; Collares, F.M. Calcium phosphates as fillers for methacrylate-based sealer. Clin. Oral Investig. 2019, 23, 4417-4423. [CrossRef] [PubMed]

48. Love, R.M. Bacterial adhesins-Their role in tubule invasion and endodontic disease. Aust. Endod. J. 2002, 28, 25-28. [CrossRef]

49. Xie, J.Y.; He, Y.; Irwin, P.L.; Jin, T.; Shi, X. Antibacterial activity and mechanism of action of zinc oxide nanoparticles against campylobacter. Appl. Environ. Microbiol. 2011, 77, 2325-2331. [CrossRef]

50. Tiwari, V.; Mishra, N.; Gadani, K.; Solanki, P.S.; Shah, N.A.; Tiwari, M. Mechanism of anti-bacterial activity of zinc oxide nanoparticle against carbapenem-resistant acinetobacter baumannii. Front. Microbiol. 2018, 9, 1218. [CrossRef]

51. Kashef, N.; Hamblin, M.R. Can microbial cells develop resistance to oxidative stress in antimicrobial photodynamic inactivation? Drug Resist. Updates 2017, 31, 31-42. [CrossRef]

52. Zanni, E.; Chandraiahgari, C.R.; De Bellis, G.; Montereali, M.R.; Armiento, G.; Ballirano, P.; Polimeni, A.; Sarto, M.S.; Uccelletti, D. Zinc oxide nanorods-decorated graphene nanoplatelets: A promising antimicrobial agent against the cariogenic bacterium streptococcus mutans. Nanomaterials 2016, 6, 179. [CrossRef]

53. Szemes, T.; Vlkova, B.; Minarik, G.; Tothova, L.; Drahovska, H.; Turna, J.; Celec, P. On the origin of reactive oxygen species and antioxidative mechanisms in Enterococcus faecalis. Redox Rep. 2010, 15, 202-206. [CrossRef] [PubMed]

54. Vidana, R.; Sullivan, A.; Billström, H.; Ahlquist, M.; Lund, B. Enterococcus faecalis infection in root canals-host-derived or exogenous source? Lett. Appl. Microbiol. 2011, 52, 109-115. [CrossRef] [PubMed]

55. Zhu, X.; Wang, Q.; Zhang, C.; Cheung, G.S.P.; Shen, Y. Prevalence, phenotype, and genotype of Enterococcus faecalis isolated from saliva and root canals in patients with persistent apical periodontitis. J. Endod. 2010, 36, 1950-1955. [CrossRef] [PubMed] 